\title{
Hydraulic calculation of reliability and safety parameters of the irrigation network and its hydraulic facilities
}

\author{
Rustam Karshiev ${ }^{*}$, Abduvoxid Urazkeldiyev, Adhamjon Rajabov, and Azizbek Ernazarov \\ Research Institute of Irrigation and Water Problems, Tashkent, Uzbekistan
}

\begin{abstract}
Nowadays, more than 155.7 thousand $\mathrm{km}$ of irrigation networks are operated by WUA, farms and clusters. $95 \%$ of irrigation networks were built and commissioned in the $80 \mathrm{~s}$ of the last centuries.

The parameters of the irrigation canals, built in the $70-80$ s of the XX century, are set for irrigation of cotton and alfalfa irrigated agriculture during the growing season 170-210 days. Irrigation networks have been designed for this crop rotation scheme.

Since 1993, the rotation scheme has changed to cotton-wheat. Irrigation networks began to operate continuously throughout the year after the transition of agricultural production to the cultivation of autumn cereals, which require irrigation from October to May. As a result, it has become difficult to carry out repair work on irrigation networks.

In addition, irrigation networks have been designed, built and operated by adapting crops to traditional irrigation systems. In recent years, large-scale work has been carried out on the widespread implementation of watersaving technologies in agriculture.
\end{abstract}

\section{Introduction}

In particular, drip irrigation on 77.5 thousand hectares, sprinkler irrigation on 1.2 thousand hectares, pulsar irrigation technology on 2.0 thousand hectares and irrigation using flexible pipes (flexible hoses) on more than 200.0 thousand hectares are widely used, and furrow irrigation is carried out on more than 300,000 hectares. This method should lead to a reduction in the number of water resources used in agriculture, as well as a decrease in the amount of water taken from canals. However, if the amount of water taken from the source decreases, technical and technological problems related to the transportation of water resources in most irrigation networks arise [1].

One solution to these scientific and technical problems will be the construction of water intakes and dams for efficient water transportation in irrigation networks. It is a topical scientific and technical issue to deliver to consumers the sufficient and necessary amount of water through the canal by effectively selecting the distance between the dams. This section presents the results of research aimed at solving these scientific and technical problems.

${ }^{*}$ Corresponding author: r.karshiev@mail.ru 


\section{Methods}

\subsection{Calculation of filtration losses in the canal}

In many cases, the method of filtration resistances is widely used in engineering calculations on a large scale to make them suitable for calculating filtration in the formation of complex flows in canals and other structures.

The basic principles of the filtration resistance method are described below. It is characterized by the possibility of replacing correctly formed boundary conditions at a certain distance with the boundary conditions of the part, which is similar to the state of the filtration water flow rate and the general view at a certain distance under conditions of a sharp change in the filtration pressure. As a result of this replacement, abrupt changes in flow are eliminated, and a flat-sized flow is formed with pressure distribution up to the formed waterproof layer. It possible to efficiently calculate the filtration processes occurring in irrigation systems, canals, reservoirs and hydraulic structures.

The execution of computational operations by the filtration resistance method is based on the hydraulic solution of problems obtained separately with the parameters obtained from laboratory and field experiments. For example, when considering filtering in a canal, the filtering current is replaced by boundary conditions that take resistance into account.

When calculating a stable filtration process, the specific water flow in one direction in the canal is determined as follows:

$$
q_{k}=T \frac{\bar{h}_{k}}{\Phi_{k}+\sqrt{\frac{T z_{*}}{\varepsilon_{I}}}}
$$

(1) formula: $T$ is average water permeability, $\mathrm{m}^{2} /$ cyт; $\bar{h}_{k}$ is difference between canal and groundwater level, $\mathrm{m} ; \Phi_{k}$ is filtration resistance pressure depending on the hydrodynamic state of the channel, $\mathrm{m} ; \varepsilon_{n}$ is evaporation rate of water. The formula for calculating the specific flow rate of water for filtration when filling the canal itself with concrete is as follows:

$$
q_{k}=T \frac{\bar{h}_{k}}{\Phi_{k}+\Phi_{o b l}+\sqrt{\frac{T z_{*}}{\varepsilon_{\Pi}}}}
$$

Formula $\Phi_{o b l}$ is additional resistance arising when the canal core is poured with concrete, $\mathrm{m}$ using the following phrases, we get:

$$
\begin{gathered}
T=k\left(h_{*}+\frac{\bar{h}_{k}}{2}\right) ; \bar{h}_{k}=h_{k}-h_{*} ; \Phi_{\kappa}=\Phi_{\kappa}^{\prime}+2 \Phi_{\kappa}^{\prime \prime} ; \Phi_{k}^{\prime}=h_{k} f_{k}^{\prime} ; \Phi_{\kappa}^{\prime \prime}=h_{k} f_{k}^{\prime \prime} ; \\
f_{k}^{\prime}=\frac{B_{k}}{2 h_{k}}-1.466 \lg \operatorname{ctg}\left(\frac{\pi B_{k}}{4 m}\right) ; f_{k}^{\prime \prime}(m)=0.733 \lg \operatorname{ctg}\left(\frac{\pi B_{k}}{4 h_{k}}\right)
\end{gathered}
$$

$k$ is filtration coefficient of soil. 
Additional resistances caused by coatings in the canal are calculated using the following formula:

$$
\Phi_{o b l}=f_{o b l} B_{k}=\frac{k}{k_{o b l}^{\prime}} \delta_{0}, \text { here: } f_{o b l}=\frac{k}{k_{o b l}^{\prime}} \frac{\delta_{0}}{B_{k}}
$$

The groundwater level around the canal is determined by the following formula: when the channel core passes through the ground

$$
h=h_{*}+h_{k}^{\prime} e^{-\bar{X}}
$$

concrete canal

$$
\begin{gathered}
h_{k}^{\prime}=h_{k}^{\prime}-\frac{q_{k}}{T} \Phi_{\kappa} \\
h_{k}^{\prime}=h_{k}^{\prime}-\frac{q_{k}}{T}\left(\Phi_{\kappa}+\Phi_{o b l}\right)=\frac{h_{k}^{\prime}}{a\left(\Phi_{\kappa}+\Phi_{o b l}\right)+1}
\end{gathered}
$$

The following parameters are used to calculate the filtration rate according to (6) or (7), if there are different soils in the two layers of the channel:

$T=k_{1}\left(h_{*}+\frac{\bar{h}_{k}}{2}\right)+k_{2} m_{2}$, e $k_{1}, k_{2}$ are filtration coefficients of soils of the first and second floors; $m_{2}$ is second floor soil thickness.

The calculation of the filtration occurring in the upper Mamurabad №8 (PK26 + 70 PK28 +80 ) of the canal is carried out using the following parameters determined in field experiments:

- canal water depth $h_{0}=1,2 \mathrm{~m}$;

- width at the water level in the canal $B_{k}=3,0 \mathrm{~m}$;

- canal depth width $b=1,5 \mathrm{~m}$;

- the water level of the first floor to the ground $h \kappa=7 \mathrm{~m}$;

- second layer soil thickness $m_{2}=18 \mathrm{~m}$;

- natural groundwater level up to the ground floor of the basement $h_{*}=5 \mathrm{~m}$;

- filtration coefficient of the base of the first floor (soil with an admixture of sandstone) $k_{l}=0.5 \mathrm{~m} /$ day;

- filtration coefficient of the first floor (with a mixture of stones) $k_{2}=5 \mathrm{~m} /$ day;

$-\xi_{0}, \varsigma_{0}$ are correction factors;

- depth of groundwater in a state of water evaporation $\mathrm{E}=0 z_{0}=2 \mathrm{~m}$;

- evaporation rate of water from ground level $\varepsilon_{n}=0,003 \mathrm{~m} /$ day;

A) Water consumption for one-sided filtration from canal is calculated by the formula (2.6.1): 


$$
\begin{aligned}
& q_{k}=T \frac{\bar{h}_{k}}{\Phi_{k}+\sqrt{\frac{T z_{*}}{\varepsilon_{\Pi}}}}=0.16 \mathrm{~m}^{2} / \text { day, } \bar{h}_{k}=h_{k}-h_{*}=7-5=2 M \\
& T=k_{1}\left(h_{*}+\frac{\bar{h}_{k}}{2}\right)+k_{2} m_{2}=94 \mathrm{~m}^{2} / \text { day, } \Phi_{\kappa}=\Phi_{\kappa}^{\prime}+2 \Phi_{\kappa}^{\prime \prime}=915.33 \mathrm{~m} \text {, } \\
& \Phi_{\kappa}^{\prime}=\xi_{0} \frac{k_{2}}{k_{1}} m f_{k}^{\prime}(m)+\frac{k_{1}-k_{2}}{k_{1}} m_{1} f_{k}^{\prime}\left(m_{1}\right)=0.33 \mathrm{~m}, m=h_{k}+m_{2}=25 \mathrm{M} \text {, } \\
& m_{1}=h_{k} \\
& f_{k}^{\prime}(m)=\frac{B_{k}}{2 m}-1.466 \lg \operatorname{ctg}\left(\frac{\pi B_{k}}{4 m}\right)=0.06 \\
& f_{k}^{\prime}\left(m_{1}\right)=\frac{B_{k}}{2 m_{1}}-1.466 \lg \operatorname{ctg}\left(\frac{\pi B_{k}}{4 m_{1}}\right)=0.14 \\
& \Phi_{k}^{\prime \prime}=\varsigma_{0} \frac{k_{2}}{k_{1}} m f_{k}^{\prime \prime}(m)+\frac{k_{1}-k_{2}}{k_{1}} m_{1} f_{k}^{\prime \prime}\left(m_{1}\right)=457.5 \mathrm{м} \text {, } \\
& f_{k}^{\prime \prime}(m)=0.733 \lg \operatorname{ctg}\left(\frac{\pi B_{k}}{4 m}\right)=0.75 \\
& f_{k}^{\prime \prime}\left(m_{1}\right)=0.733 \lg \operatorname{ctg}\left(\frac{\pi B_{k}}{4 m_{1}}\right)=0.178 \quad Q_{\phi}=2 q_{k}=0.32 \mathrm{~m}^{2} / \text { day, } \\
& \chi=b+2 h_{0} \sqrt{1+m^{2}}=5.82 \mathrm{~m}, Q_{\phi 1 \mathrm{~m} 2}=\frac{Q_{\phi}}{\chi}=54.98 \mathrm{l} / \mathrm{day}^{*} \mathrm{~m}^{2}
\end{aligned}
$$

Calculation of filtration in a concrete-lined canal in motion mode. The following formula is recommended for the flow rate of one-sided specific filtration when the canal core is filled with concrete.

$$
q_{k}=T \frac{\bar{h}_{k}}{\Phi_{k}+\Phi_{o b l}+\sqrt{\frac{T z_{*}}{\varepsilon_{\Pi}}}}
$$

$\bar{h}_{k}, T, \Phi_{k}$ is calculated by the above formulas. Additional filtration resistances in the concrete state are calculated by the formula $\Phi_{\text {обл }}$ (9). Coating thickness $\delta_{0}$, in all cases, it is assumed that the size of the calculations is $0.06 \mathrm{~m}$.

$$
\begin{gathered}
K_{o b l}=0.0013 \mathrm{~m} / \mathrm{day}, \Phi_{o b l}=\frac{k_{1}}{k_{o b l}^{\prime}} \delta_{0}=23.1 \mathrm{~m} \\
q_{k}=T \frac{\bar{h}_{k}}{\Phi_{k}+\Phi_{o b l}+\sqrt{\frac{T z_{*}}{\varepsilon_{\Pi}}}}=0.15 \mathrm{~m}^{2} / \text { day }
\end{gathered}
$$




$$
Q_{\phi}=2 q_{k}=0.3 \mathrm{~m}^{2} / \text { day, } \chi=b+2 h_{0} \sqrt{1+m^{2}}=5.82 \mathrm{~m}, Q_{\phi 1 \mathrm{~m} 2}=\frac{Q_{\phi}}{\chi}=51.541 / \mathrm{day}^{*} \mathrm{~m}^{2}
$$

The degree of effectiveness of the coating is determined by the following formula:

$$
K_{o b l}=\frac{Q_{\phi . z e m}}{Q_{\phi . \mathrm{obl}}}=1.06
$$

When there is a geosynthetic coating:

$$
\begin{gathered}
K_{o b l}=0.00000864 \mathrm{~m} / \mathrm{day}, \Phi_{o b l}=\frac{k_{1}}{k_{o b l}^{\prime}} \delta_{0}=3472 \mathrm{~m}, \\
q_{k}=T \frac{\bar{h}_{k}}{\Phi_{k}+\Phi_{o b l}+\sqrt{\frac{T z_{*}}{\varepsilon_{I I}}}}=0.10 \mathrm{~m}^{2} / \mathrm{day}, Q_{\phi}=2 q_{k}=0.2 \mathrm{~m}^{2} / \mathrm{day}, \\
\chi=b+2 h_{0} \sqrt{1+m^{2}}=5.82 \mathrm{~m}, Q_{\phi 1 \mathrm{~m} 2}=\frac{Q_{\phi}}{\chi}=34.82 \mathrm{l} / \mathrm{day}^{*} \mathrm{M}^{2}, \\
K_{o b l}=\frac{Q_{\phi . \mathrm{zem}}}{Q_{\phi . \mathrm{obl}}}=1.57
\end{gathered}
$$

a. Calculation of the state of reliability of an irrigation canal.

When using canals, it is important to assess quantitative indicators of the state of reliability associated with such adverse effects as wear of canal dams under the influence of dangerous filtration currents, subsidence, and elevation of canal sections relative to the area.

The use of the Bayesian method to quantify the reliability of irrigation canals yields good results. In this method, based on field experimental observations and statistics, a diagnostic hypothesis can be selected with a high probability, which allows the system to assess the state of reliability.

Bayes' formula is:

$$
P\left(D_{i} / K_{j}\right)=\frac{P\left(D_{i}\right) P\left(K_{j} / D_{i}\right)}{\sum_{s=1}^{n} P\left(D_{s}\right) P\left(K_{j} / D_{s}\right)}
$$

where: $P\left(D_{i}\right)-D_{i}$ is initial probability of diagnosis;

$P\left(K_{j} / D_{i}\right)-D_{i}$ is the probability of the appearance of signs $K_{j}$ on objects with a condition.

$\sum_{s=1}^{n} P\left(D_{s}\right) P\left(K_{j} / D_{s}\right)$ is the sum of the probabilities of the occurrence of events. 
Three main diagnostic indicators affect the reliability and safety of risers: $\mathrm{K}_{1}$ is location of the canal dam above the water level; $\mathrm{K}_{2}$ is collapse of the canal dam; $\mathrm{K}_{3}$ is filtering gradient from the base and body of the canal.

Taking the above into account, the issue was resolved as follows:

$P_{1}=0.3$ the likelihood of an emergency as a result of the rise of water from the canal dam;

$P_{2}=0.15$ the likelihood of an accident as a result of a canal dam break;

$P_{3}=0.05$ the probability of an accident as a result of filtering from the canal.

Based on the above diagnostic parameters, the following was determined:

$$
\begin{gathered}
K_{1}=0.50 K_{2}=0.40 K_{3}=0.05 \\
P\left(A_{i}\right)=\frac{K_{i}}{N} \text { including, } \\
N=K_{1}+K_{2}+K_{3}=0.50+0.40+0.05=0.95 \text { determined, } \\
P\left(B / A_{i}\right)=P_{i} \text { and } \\
P\left(A_{2} / B_{i}\right)=\frac{P\left(B / A_{2}\right) P\left(A_{2}\right)}{P\left(A_{1}\right) P\left(B / A_{1}\right)+P\left(A_{2}\right) P\left(B / A_{2}\right)+P\left(A_{3}\right) P\left(B / A_{3}\right)} \text { for } \\
P\left(A_{2}\right)=\frac{K_{2}}{N}=\frac{0.4}{0.95} \quad P\left(B / A_{2}\right)=P_{2}=0.15 \text { values have been }
\end{gathered}
$$

received.

$$
\begin{array}{ll}
P\left(A_{1}\right)=\frac{K_{1}}{N}=\frac{0.5}{0.95} & P\left(B / A_{1}\right)=P_{1}=0.3 \\
P\left(A_{3}\right)=\frac{K_{3}}{N}=\frac{0.05}{0.95} & P\left(B / A_{3}\right)=P_{3}=0.05
\end{array}
$$

The probability of an accident as a result of a breakthrough of a canal dam is determined:

$$
P\left(A_{2} / B_{i}\right)=\frac{P\left(B / A_{2}\right) P\left(A_{2}\right)}{P\left(A_{1}\right) P\left(B / A_{1}\right)+P\left(A_{2}\right) P\left(B / A_{2}\right)+P\left(A_{3}\right) P\left(B / A_{3}\right)}=0.61
$$

As a result of calculations made based on data on the tributaries of the Upper Mamurabad canal, it should be noted that the reliability of the aboveground part of the canal is normal. The probability of an accident as a result of a canal dam break is 0.61 .

\section{Results and Discussion}

Hydraulic calculation of the length between dams in concrete and soil ditches, taking into account the filtration, evaporation and technological costs of water in the process of transportation of water resources through the irrigation canal, as well as the required efficiency of irrigation canals. The research object is the interval between № 8 and №9 branches of the Upper Mamurabad canal in the territory of Karasuv WUA of the 
Kurgantepa district of Andijan region. The hydraulic parameters of the irrigation network and the irrigated area are 30.5 hectares.

The parameters of the canal supplying water to the research object are as follows: the slope of the canal side walls $\boldsymbol{m}=\mathbf{1 . 5}$, coefficient of roughness $\boldsymbol{n}=\mathbf{0 . 0 2 2 5}$, slope along the length of the canal $\boldsymbol{i}=\mathbf{0 . 0 0 0 5}$, water consumption $Q=0.5 \boldsymbol{M}^{3} / c$.

\section{Conclusions}

As an object of research, the Bayesian method was used to assess the quantitative indicators of the state of reliability associated with the adverse impact of the dams of the Upper Mamurabad canal under the influence of dangerous filtration currents, subsidence, the elevation of the canal sections relative to the area. According to the calculation results, the reliability of the aboveground part of the canal is normal. The probability of an accident that could have occurred due to a breakthrough of the canal dam was 0.61 .

\section{References}

1. Chen Xi, Khamraev Sh.R. et al, Research of agromeliorative parameters of the Amu Darya river basin territories in the context of climate change in Central Asia, Yangi asr avlodi, monograph, pp. 190 - 199. (2019).

2. Bandurin M. A. et al. The efficiency of impervious protection of hydraulic structures of irrigation systems, International scientific and practical conference" Agro-SMARTSmart solutions for agriculture"(Agro-SMART 2018). - Atlantis Press, (2018).

3. Bazarov D. et al. Water flow motion in the vehicle of main channels, IOP Conference Series: Materials Science and Engineering. - IOP Publishing, 883. (1). (2020).

4. George B. et al. An integrated hydro-economic modelling framework to evaluate water allocation strategies I: Model development. Agricultural water management. 98. (5). pp. 733-746. (2020).

5. Jong C. G., Leu S. S. Bayesian-network-based hydro-power fault diagnosis system development by fault tree transformation, Journal of Marine Science and Technology. 21. (4). pp 367-379. (2013).

6. Volkov V. I., Snezhko V. L., Kozlov D. V. Prediction of safety level of low-head and ownerless hydraulic structures, Power Technology and Engineering. 53. (1). pp. 2328. (2019).

7. Inam A. et al. Parameter estimation and uncertainty analysis of the Spatial Agro Hydro Salinity Model (SAHYSMOD) in the semi-arid climate of Rechna Doab, Pakistan, Environmental Modelling \& Software. 94. pp. 186-211.(2017)

8. Fedorov M. P. et al. The simulation models of river flow management by a system of flood control facilities, Magazine of Civil Engineering.76. (8).(2017).

9. YURCHENKO I. INFORMATION SUPPORT SYSTEM DESIGNED FOR TECHNICAL OPERATION PLANNING OF RECLAMATIVE FACILITIES journal of Theoretical \& Applied Information Technology. -. - T. 96. (5). (2018).

10. Rehman S., Al-Hadhrami L. M., Alam M. M. Pumped hydro energy storage system, A technological review//Renewable and Sustainable Energy Reviews. 44. pp. 586-598. (2015).

11. Guba A., Makai M., Pál L. Statistical aspects of best estimate method-I, Reliability engineering \& system safety. 80. (3). pp. 217-232. (2003). 
12. Gafforov K. S. et al. The Assessment of Climate Change on Rainfall-Runoff Erosivity in the Chirchik-Akhangaran Basin, Uzbekistan, Sustainability. 12. (8). pp 3369. (2020).

13. Sidike A. et al. Investigating alternative climate data sources for hydrological simulations in the upstream of the Amu Darya River, Water. 8. (10). p. 441. (2016).

14. Omurakunova G. et al. Expansion of Impervious Surfaces and Their Driving Forces in Highly Urbanized Cities in Kyrgyzstan, International journal of environmental research and public health. 17. (1). pp 362. (2020).

15. Khaydar D. et al. Investigation of crop evapotranspiration and irrigation water requirement in the lower Amu Darya River Basin, Central Asia, Journal of Arid Land. 13. (1). pp. 23-39. (2021).

16. Luo M. et al. Spatiotemporal characteristics of future changes in precipitation and temperature in Central Asia, International Journal of Climatology. 39. (3). pp. 15711588. (2019).

17. Ramesh P. et al. Hydrochemical Characteristics and Macrophytes In The Betana Lake, Eastern Nepal, Scientific and technical journal "Sustainable Agriculture", 3 (7). (2020).

18. Clarke D. et al. Analysis of the hydraulics of the irrigation canals of Otrar, Kazakhstan, Water Science and Technology: Water Supply. 10. (3). pp. 453-461. (2010).

19. Xingye Z., Bin C., Qin T. Head loss hydraulic calculation step by step for light and small sprinkler irrigation system, Journal of drainage and irrigation machinery engineering. 2. (2011).

20. Sharu E. H., Ab Razak M. S. Hydraulic Performance and Modelling of Pressurized Drip Irrigation System, Water. 2020. 12. (8). p. 2295. (2020). 